\section{First-in-class BTK inhibitor Imbruvica gets CLL approval}

Pharmacyclics first-in-class BTK inhibitor Imbruvica (ibrutinib) received expanded approval by the US Food and Drug Administration (FDA) for chronic lymphocytic leukemia (CLL) in July. Imbruvica, a selective inhibitor of Bruton's tyrosine kinase, which slows the development of B-cell malignancies, was approved in 2013 for mantle cell lymphoma, and in early 2014 , it was given accelerated approval for CLL, based on a phase $1 / 2 \mathrm{~b}$ clinical trial of $48 \mathrm{CLL}$ patients. In July, the FDA expanded the approval to CLL patients with a deletion in chromosome 17 , a form of CLL that responds poorly to standard treatment. The expanded approval, which was announced two months ahead of the application's Prescription Drug User Fee Act (PDUFA) date, was based on a trial with 391 previously treated patients, 127 of whom had the chromosome 17 deletion. It's been a particularly good year for CLL with three other CLL drugs receiving approval through the FDA's breakthrough drug designation since last November: Roche's Gazyva (obinutuxumab), GlaxoSmithKline and Genmab's Arzerra (ofatumumab) and Gilead's Zygelig (idelalisib).

\section{Google Ventures launches London office}

Google announced in July that its venture capital arm Google Ventures will be looking to spend $\$ 100$ million on budding European companies, including life sciences. The new office will be located in the area of London known as Tech City. The software giant described the European startup scene as having enormous potential, noting the sum is an initial funding. In June, Index Ventures launched an even bigger fund $€ 400$ ( $\$ 535.7$ ) million, also dedicated to seeding early-stage technology investments.

\section{6 "We started off realizing that New York City should be the center of} biotechnology and it wasn't and that one of the reasons for that was that there wasn't appropriate space for companies."

Eva Cramer, president of BioBAT, Brooklyn, New York's biotech facility. Yet, seven years into the project, the nine-story biotech facility in the Brooklyn Army Terminal, remains largely unoccupied. (The Wall Street Journal, 14 July 2014)

\footnotetext{
"Valuation metrics in some sectors do appear substantially stretched-particularly those for smaller firms in the social media and biotechnology industries, despite a notable downturn in equity prices for such firms early in the year." Federal Reserve Board chair Janet Yellen in testimony before the US Senate Finance Committee. Healthcare indices immediately dropped roughly $2 \%$, a greater decline than the broader markets that day. (Business Insider, 15 July 2014)
}

12-14 minutes, a timing similar to that of the insulin surge in healthy individuals, and faster than rapid-acting insulin analogs like Eli Lilly's Humalog or Pfizer's Novolog that typically take 40-50 min.

The FDA advisory panel meeting held in April voted in favor of Afrezza, after reviewing efficacy and safety data from 3,017 patients, including 1,026 with T1D and 1,991 with T2D. In the trial, at 24 weeks, Afrezza reduced glycosylated hemoglobin A1c levels to the prespecified end point of $0.4 \%$ in both groups. Although hemoglobin A1c reduction was inferior to that of injected insulin Novolog among T1D patients, it was sufficiently close to warrant approval. In T2D patients, who were also taking glucose-lowering medications, the reduction was superior to placebo.

Even so, the advisory committee had a few concerns, says William J. Calhoun, professor of internal medicine and vice chairman for research at the University of Texas Medical Branch, Galveston, who was part of the panel. The Technosphere particles have the potential to lead to asthma-like symptoms and could also cause bronchospasms. As a consequence, it is contraindicated in people with asthma and chronic obstructive pulmonary disease. It is also not recommended for smokers.

The potential lung cancer risk is also a worry. In MannKind's trial, four individuals developed lung cancer in the Afrezza group, compared with no cases in the control group. MannKind also agreed to conduct long-term studies to assess whether long-term use of inhaled insulin increases the risk of lung cancer or impairs lung function. Insulin is known to be potentially carcinogenic.

The committee also raised concerns about patient behavior. People might choose to abandon their basal insulin injections entirely in favor of mealtime Afrezza. This could lead to poor glucose control. Calhoun nevertheless voted in favor of approval because he believes people with diabetes deserve choice. "Diabetics have a tough row to hoe with finger sticks and injections, and the product appears safe and effective, and it would reduce the burden of injection," says Calhoun. Immediately after the advisory board meeting, several patients approached him outside his hotel and thanked him for the committee's vote. "In the dozens of [FDA] committees I've been on, I've never had patients thank us for what we did. I think [Afrezza] is going to be pretty impactful."

Other prandial insulin products are injectable, like Eli Lilly's Humulin and Novo Nordisk's Novolin. These reach peak concentrations in about 30 minutes and take three to six hours to clear. Sanofi also markets an ultrafast product Apidra (insulin glulisine), a human insulin analog, that is more rapid in onset and shorter duration compared with regular human insulin.

For those who fear needles, the delivery mode could be attractive. But Robert Ratner, chief scientific and medical officer of the New York-based American Diabetes Association, thinks the inhaled insulin appeal is its ease of use in public spaces, like restaurants. "There is less of a social impediment to taking an inhaler; we'll do better because people will take their medicine. This is a matter of improving adherence," he says. Joel Zonszein, professor of clinical medicine and director of the diabetes program at Montefiore Medical Center in the Bronx, New York, thinks that needle aversion may not be an important advantage, noting that injected insulin products have become much easier to use and nearly painless, and patients with T1D are generally used to injecting long-lasting basal insulin and supplemental, mealtime bolus insulin. "(Type 1 diabetics) are very pedantic. They grow up with diabetes, they're very engaged with their disease, and it's difficult to convince them to make any changes," he says.

James is more optimistic. He expects Afrezza to be adopted initially in T1D diabetes as mealtime insulin. "Given the option, patients would rather not inject themselves. I definitely think there's a need for a noninvasive form of insulin," he says.

In type 2 diabetes, clinicians may choose to use Afrezza after patients have failed on one or two oral agents and before going on to injected insulin. "Prandial insulin is the icing. Most don't need it because we are using the newer medications," says Zonszein. Despite new alternatives, many individuals with T2D have poor blood sugar control, says Matt Pfeffer, CFO of MannKind. "Surveys show doctors have a hard time getting patients to start insulin, even when (blood sugar) numbers show they should. It's a major hurdle to move to insulin from a pill. Shots aren't painful, but there's a stigma associated with it. There's not the same stigma with an inhaler," he says.

A survey of endocrinologists and primary care physicians commissioned by Brinson Patrick found that the latter group see Afrezza as a third-line therapy in T2D. Endocrinologists said they were likely to use it to replace existing insulins only.

MannKind's Pfeffer says the company is expecting varied responses to its new product. "No one form of insulin is likely to be for everybody. The market is so large that there's room for everyone." The current global insulin market is about $\$ 15$ billion annually. "We just need to improve patient outcomes," Pfeffer says. The partners plan to launch Afrezza in the US in 1Q15.

Jim Kling Bellingham, Washington 